\title{
High-frequency urban measurements of molecular hydrogen and carbon monoxide in the United Kingdom
}

\author{
A. Grant, K. F. Stanley, S. J. Henshaw, D. E. Shallcross, and S. O'Doherty \\ School of Chemistry, University of Bristol, UK \\ Received: 9 December 2009 - Published in Atmos. Chem. Phys. Discuss.: 18 January 2010 \\ Revised: 27 April 2010 - Accepted: 10 May 2010 - Published: 25 May 2010
}

\begin{abstract}
High-frequency measurements of atmospheric molecular hydrogen $\left(\mathrm{H}_{2}\right)$ and carbon monoxide $(\mathrm{CO})$ were made at an urban site in the United Kingdom (UK) from mid-December, 2008 until early March, 2009. Very few measurements of $\mathrm{H}_{2}$ exist in the urban environment, particularly within the UK, but are an essential component in the assessment of anthropogenic emissions of $\mathrm{H}_{2}$ and to a certain extent $\mathrm{CO}$. These data provide detailed information on urban time-series, diurnal cycles as well as sources and sinks of both $\mathrm{H}_{2}$ and $\mathrm{CO}$ at urban locations. High-frequency data were found to be strongly influenced by local meteorological conditions of wind speed and temperature. Diurnal cycles were found to follow transport frequency very closely due to the sites proximity to major carriageways, consequently a strong correlation was found between $\mathrm{H}_{2}$ and $\mathrm{CO}$ mole fractions. Background subtracted mean and rush hour molar $\mathrm{H}_{2} / \mathrm{CO}$ emission ratios of $0.53 \pm 0.08$ and $0.57 \pm 0.06$ respectively, were calculated from linear fitting of data. The scatter plot of all $\mathrm{H}_{2}$ and $\mathrm{CO}$ data displayed an unusual two population pattern, thought to be associated with a large industrial area $85 \mathrm{~km}$ to the west of the site. However, the definitive source of this two branch pattern could not be fully elucidated. $\mathrm{H}_{2}$ emissions from transport in the UK were estimated to be $188 \pm 39 \mathrm{Gg} \mathrm{H}_{2} / \mathrm{yr}$, with $8.1 \pm 2.3 \mathrm{Tg} / \mathrm{yr}$ of $\mathrm{H}_{2}$ produced from vehicle emissions globally. $\mathrm{H}_{2}$ and $\mathrm{CO}$ deposition velocities were calculated during stable night-time inversion events when a clear decay of both species was observed. $\mathrm{CO}$ was found to have a much higher deposition velocity than $\mathrm{H}_{2}$, $1.3 \pm 0.8 \times 10^{-3}$ and $2.2 \pm 1.5 \times 10^{-4} \mathrm{~m} \mathrm{~s}^{-1}(1 \sigma)$ respectively, going against the law of molecular diffusivity. The source of this unusual result was investigated, however no conclusive explanation was found for increased loss of $\mathrm{CO}$ over $\mathrm{H}_{2}$ during stable night time inversion events.
\end{abstract}

Correspondence to: A. Grant (aoife.grant@bristol.ac.uk)

\section{Introduction}

Atmospheric mixing ratios of molecular hydrogen $\left(\mathrm{H}_{2}\right)$, reported to be stable over the past 14-years (Grant et al., 2010), may be altered with the possible introduction of $\mathrm{H}_{2}$ as an energy carrier. This has provoked increased interest in the $\mathrm{H}_{2}$ budget as it may result in increased $\mathrm{H}_{2}$ emissions due to leakages during transport, distribution and usage of the fuel, thereby altering tropospheric and stratospheric chemistry. Major sources of $\mathrm{H}_{2}$ consist of VOC oxidation ( $\sim 50 \%)$, biomass burning ( $\sim 20 \%)$ and fossil fuel combustion in transport and industry $(\sim 25 \%)$ (Novelli et al., 1999; Price et al., 2007; Xiao et al., 2007). The latter is thought to be the main emission source significantly altered with introduction of a $\mathrm{H}_{2}$ economy. Current estimates of $\mathrm{H}_{2}$ emission from transport and industry are based on inventories of carbon monoxide emissions combined with emission ratios of $\mathrm{H}_{2} / \mathrm{CO}$ from transport, which have been found to vary with engine and vehicle type (Vollmer et al., 2007). Although numerous studies have reported $\mathrm{H}_{2} / \mathrm{CO}$ ratios from road transport sources (Hammer et al., 2009 and references therein) there is a paucity of $\mathrm{H}_{2} / \mathrm{CO}$ ratio measurements from other sources such as aviation, domestic heating and industry.

The major loss of $\mathrm{H}_{2}$ is from its poorly constrained biologically active soil sink, contributing 70-80\% (Novelli et al., 1999; Price et al., 2007; Sanderson et al., 2003; Xiao et al., 2007) of its total loss, whilst reaction with the hydroxyl $(\mathrm{OH})$ acts as a minor sink. $\mathrm{H}_{2}$ deposition to the soil is particularly difficult to quantify as it has been found to vary depending on a number of parameters such as soil moisture, temperature, porosity, diffusivity and type (Schmitt et al., 2009; Yonemura et al., 1999). It is thus vital to accurately quantify the magnitude of the soil sink in different areas and soil types to accurately estimate the magnitude of this loss process.

Carbon monoxide (CO) is one of the key components controlling the oxidative capacity of the troposphere by reacting with the $\mathrm{OH}$ radical, which is its primary loss route. Uptake

Published by Copernicus Publications on behalf of the European Geosciences Union. 


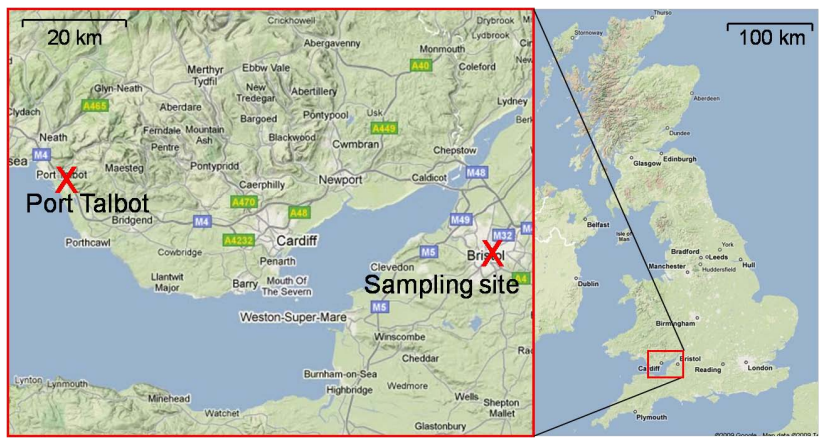

Fig. 1. Sampling site location in Bristol's city centre in the United Kingdom and the location of Port Talbot to the west of the site.

by soil micro-organisms contributes up to $10 \%$ of its loss (Bergamaschi et al., 2000). CO is also emitted by soils which results in a net global balance of uptake and production in soil (Conrad, 1988). However, soils in temperate environments have been found to primarily show $\mathrm{CO}$ uptake rather than emission (Moxley and Smith, 1998).

Continuous high-frequency measurements of $\mathrm{H}_{2}$ and $\mathrm{CO}$ were made in Bristol, United Kingdom (UK) from December 2008 to March 2009 at an urban city centre location. To our knowledge they represent the first published set of continuous measurements of $\mathrm{H}_{2}$ in the UK. The presented data and their analyses provide essential information on local sources and sinks of both $\mathrm{H}_{2}$ and $\mathrm{CO}$ which may aid in the assessment of the impact of a future $\mathrm{H}_{2}$ economy.

\section{Experimental}

\subsection{Sampling location}

Semi-continuous measurements of $\mathrm{H}_{2}$ and $\mathrm{CO}$ in ambient air have been performed using an automated, high-frequency system sampling in the city centre of Bristol, UK (Fig. 1) from mid December 2008 to early March 2009. The sampling site $\left[51^{\circ} 27^{\prime} \mathrm{N}, 2^{\circ} 36^{\prime} \mathrm{W} ; 62 \mathrm{~m}\right.$ above sea level] located at the Atmospheric Chemistry Research Group in the University of Bristol is representative of urban conditions (Khan et al., 2009; Rivett et al., 2003). Air quality at this urban sampling site is dominated by traffic emissions as it sits close to a number of major carriageways, which act as busy and often congested commuter routes to and from the city centre. With a population of nearly 500000 Bristol is the UK's sixth largest city. The city centre sits in a basin like depression surrounded by hills on each side. Two major motorways run nearby the city, with a high volume of local traffic. These combined effects often result in pollutant build-up during stable high pressure systems.

\subsection{Analytical method and calibration}

A commercial gas chromatograph (Peak Performer 1 (PP1), Trace Analytical, Inc., California, USA) was used to measure $\mathrm{H}_{2}$ and $\mathrm{CO}$. This instrument is fitted with a mercuric oxide bed and, following mercury's reduction by $\mathrm{H}_{2}$ or $\mathrm{CO}$, the ensuing vapour is measured by UV photometry. A customised sample introduction system was fitted to the PP1 very similar to that reported by Grant et al. (2010) which is used at one of the five Advanced Global Atmospheric Gases Experiment (AGAGE) measurement sites at Mace Head, Ireland. This customised sample introduction system enabled continuous, high frequency, and concurrent analysis of air and standard samples. The analysis sequence consisted of an air sample followed by a standard to determine and correct for instrumental drift, resulting in 72 fully calibrated air samples per day. A carrier gas flow of $20 \mathrm{ml} / \mathrm{min}$ of synthetic air is passed through a Sofnocat cleanup trap to remove any trace $\mathrm{CO}$ impurities prior to use. Each sample is dried prior to separation using a permeation Nafion drier (Permapure, USA). Once dried the sample is flushed through the $1 \mathrm{ml}$ sample loop and allowed to decay to ambient pressure, before injection onto two isothermal packed columns. The pre-column, used to protect the main column from contamination by gases which adsorb to the surface, is held a $105^{\circ} \mathrm{C}$, as is the main column, both using standard PP1 column combination with Unibeads $1 \mathrm{~S}, 60 / 80$ mesh and molecular sieve $5 \AA$, 60/80 mesh, respectively. Once $\mathrm{H}_{2}$ and $\mathrm{CO}$ have been separated on the main column they are analysed by the mercury detector. All $\mathrm{H}_{2}$ and $\mathrm{CO}$ peaks were integrated by height using customised software (GCWerks) developed for instruments in the AGAGE network, mole fractions were determined relative to a working standard also known as the quaternary standard. Quaternarys are filled by compressing background ambient air at Mace Head, Ireland into $35 \mathrm{~L}$ electropolished stainless steel canisters (Essex Cryogenics, Missouri, USA) using a modified oil-free compressor (SA-3, RIX California, USA). The internal surfaces of the cylinder are electropolished to remove active sites on the surface of the stainless steel. One of these calibrated quaternary standards used in the AGAGE network was used in the Bristol urban sampling campaign. $\mathrm{H}_{2}$ and $\mathrm{CO}$ measurements were referenced against a calibration scale developed at CSIRO (Commonwealth Scientific and Industrial Research Organisation). Inter-calibrations have been carried out between CSIRO and a scale developed at the Max Plank Institute (MPI) in Jena (Jordan and Steinberg, 2010). This scale was developed for the Eurohydros project to enable a network of calibrated measurements across Europe. Good agreement was found, with MPI values approximately $16 \mathrm{ppb} \mathrm{H}_{2}$ higher than the CSIRO scale (Grant et al., 2010).

Due to the non-linear response of the PP1 detector, linearity testing was carried out during the reported measurement period. This was completed using a high concentration reference gas (BOC Speciality gases Ltd., Surrey, UK) which was 


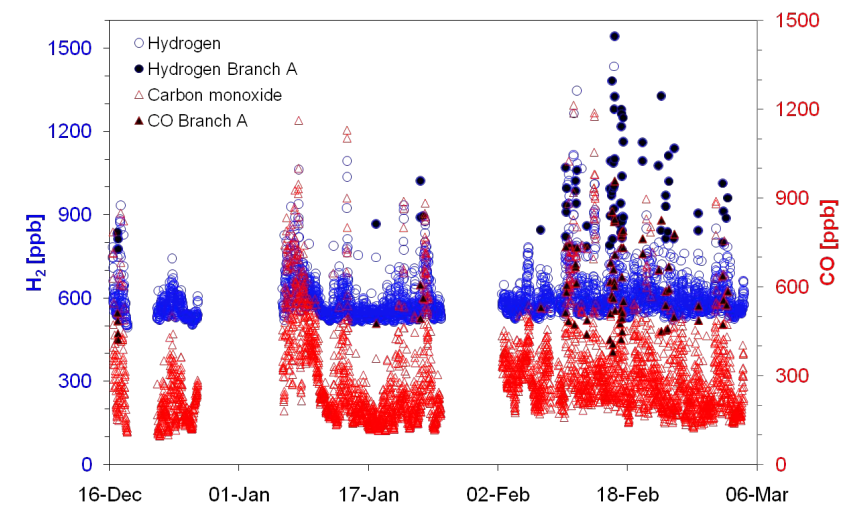

Fig. 2. Urban air measurements for $\mathrm{H}_{2}$ and $\mathrm{CO}$ from the 15 th of December 2008 until the 4th of March 2009 measured at Bristol in the United Kingdom.

dynamically diluted with zero air to the range of atmospheric concentrations by means of a custom made dynamic dilution unit. Results provided measurements for the non-linearity correction thus producing an equation to correct data for nonlinearity. A maximum internal reproducibility $(1 \sigma)$ of $5 \mathrm{ppb}$ and $1 \mathrm{ppb}$ was found for $\mathrm{H}_{2}$ and $\mathrm{CO}$ respectively, assuming average concentrations of $500 \mathrm{ppb}_{2}$ and $120 \mathrm{ppb} \mathrm{CO}$ determined from recurrent working standard analyses.

\section{Results and discussion}

The full record of high-frequency $\mathrm{H}_{2}$ and $\mathrm{CO}$ observations taken at an urban site in Bristol from mid-December 2008 to early March 2009 are shown in Fig. 2. This dataset contains $\sim 80 \%$ of the possible measurements taken over this period with segments of missing data due to instrumental problems. Overall accuracy on measurements is within $\pm 2 \%$, this takes into account standard to standard reproducibility, uncertainties in non-linearity corrections and scale propagation. Over the entire measurement period $\mathrm{H}_{2}$ was found to range from a minimum of $494 \mathrm{ppb}$ to a maximum of $1544 \mathrm{ppb}$ with a mean $( \pm 1 \sigma)$ mole fraction of $601 \pm 92 \mathrm{ppb}$, whilst CO showed a mean of $291 \pm 151 \mathrm{ppb}$ with a range of 96-1214 ppb.

\subsection{Diurnal variations}

Anthropogenic emissions, particularly from the transport sector were found to have a significant effect on the shortterm variability of $\mathrm{H}_{2}$ and $\mathrm{CO}$, evident in Fig. 3, a plot of a six day period of high-resolution $\mathrm{H}_{2}$ and $\mathrm{CO}$ mole fractions where nearly every peak in $\mathrm{H}_{2}$ coincides with elevated levels of $\mathrm{CO}$. In this plot mole fractions of $\mathrm{H}_{2}$ and $\mathrm{CO}$ are also seen to vary with wind conditions. In Fig. 3 mole fractions of $\mathrm{H}_{2}$ and $\mathrm{CO}$ are seen to rise sharply during morning and evening rush hours, approximate times of which are highlighted in yellow and green, respectively. The diurnal variation is however severely affected by meteorology. A rise

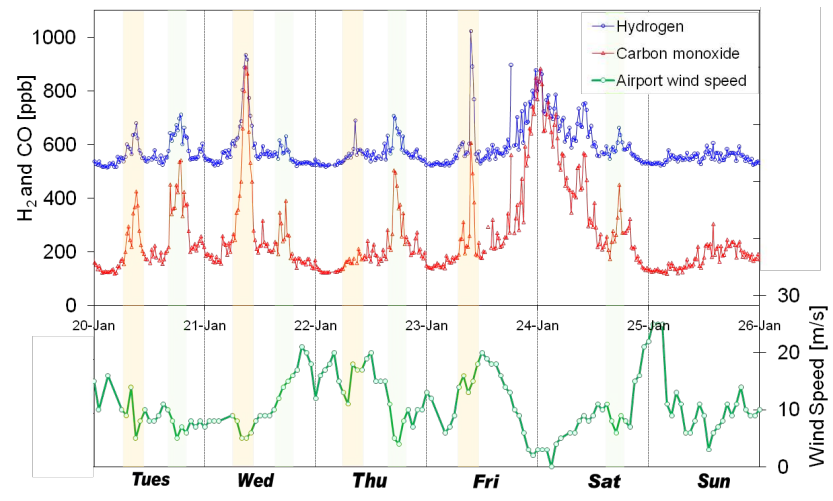

Fig. 3. $\mathrm{H}_{2}$ and $\mathrm{CO}$ mole fractions and wind speed over a six day period in January 2009, with rush hours highlighted in yellow for morning and green for evening.

in wind speed on Wednesday evening and Thursday morning leads to lower $\mathrm{H}_{2}$ and $\mathrm{CO}$ mole fractions than expected. High wind speeds at midday on Friday also reduce the amplitude of the evening rush hour peak. Overnight on Friday a large elevation of $\mathrm{H}_{2}$ and $\mathrm{CO}$ is observed. Low wind speeds overnight combined with the expected emissions from Friday evening related transport both contribute to this large elevation. Overnight on Saturday the expected traffic peak due to night life associated traffic is not observed due to high wind speeds (e.g. Martin et al., 2008). The effects of both wind speed and temperature on $\mathrm{H}_{2}$ and $\mathrm{CO}$ observations are shown in Fig. 4. Low temperatures in winter act to reduce the height of boundary layer. Pollutants are then trapped in a smaller volume resulting in the observation of elevated $\mathrm{H}_{2}$ and $\mathrm{CO}$ mole fractions. As Bristol is located in a bowl shaped depression pollutants can easily build up. High wind speeds which increase turbulence act to dilute pollutants by bringing clean air for rural areas which mixes with polluted urban air.

Figure 5 illustrates hourly mean $\mathrm{H}_{2}$ and $\mathrm{CO}$ mole fractions separated into weekdays, Saturdays and Sundays shown in local winter time (GMT). Highest mole fractions for both $\mathrm{H}_{2}$ and $\mathrm{CO}$ were observed during morning and evening rush hours. Rush hour time periods were verified by statistical traffic count data provided by Bristol City Council (2009). These are produced by a combination of manual traffic counts, carried out across central Bristol during the same week every year on mid-week days, and through the use of automatic traffic counters. Traffic flow data shows morning rush hour beginning at 07:00, peaking from 07:30 to $08: 45$ and dropping to baseline levels by 09:30. Evening rush hour is evident from traffic count data by a slow increase in traffic from 15:00, with traffic flow peaking at 17:30 and dropping off at 18:30. Mean mole fractions of $646 \mathrm{ppb} \mathrm{H}_{2}$, $390 \mathrm{ppb} \mathrm{CO}$ for morning rush hours, and $630 \mathrm{ppb}_{2}$ and $341 \mathrm{ppb} \mathrm{CO}$ were observed during evening rush hours. $\mathrm{H}_{2}$ mole fractions are seen to fall from midnight onwards, due to uptake by soil enzymes but also due to dilution caused 


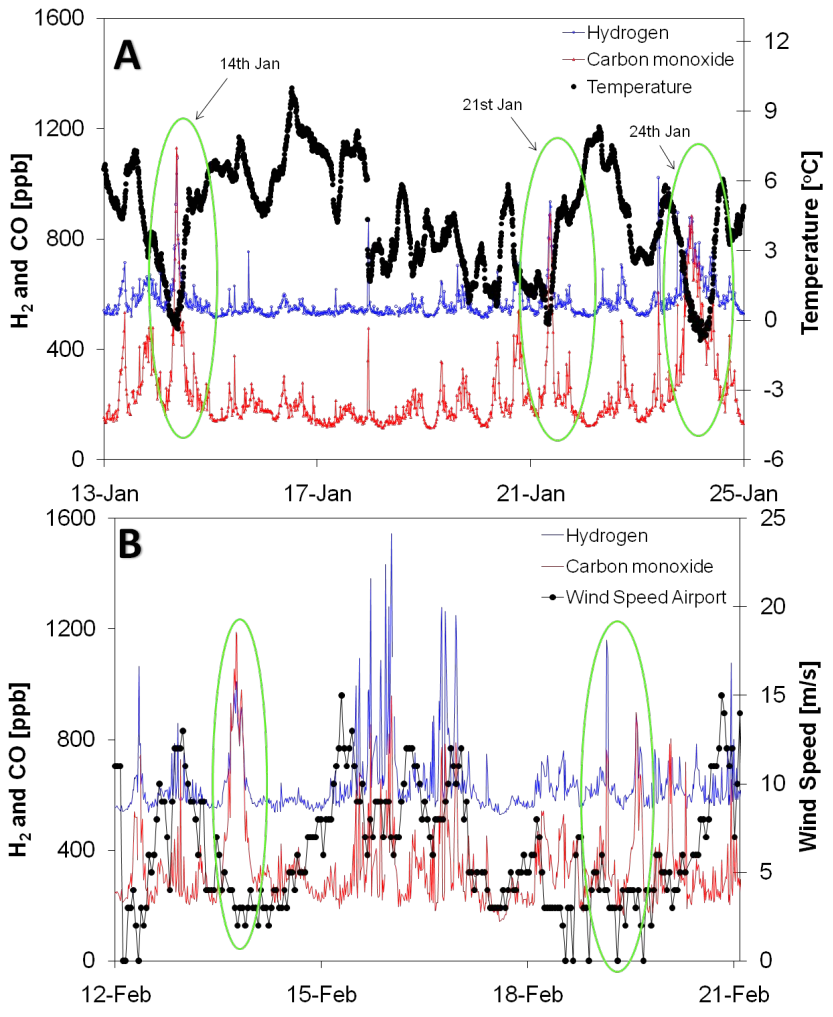

Fig. 4. $\mathrm{H}_{2}$ and $\mathrm{CO}$ mole fractions plotted with (a) temperature and (b) wind speed.

by dispersion within the boundary layer (Steinbacher et al., 2007). $\mathrm{H}_{2}$ mole fractions are seen to rise in a delayed pattern in comparison with traffic flow data. Morning peaks in $\mathrm{H}_{2}$ and $\mathrm{CO}$ reach their highest from 09:00 to 10:00, an hour and a half later than peak morning traffic flow. After this time, transport emissions decrease and with the additional effect of stronger vertical mixing at this time, dilution with background air and $\mathrm{H}_{2}$ deposition, the resulting weekday and weekend minimum is seen from 1-3 p.m. Evening rush hour peaks of $\mathrm{H}_{2}$ are wider than those observed during the morning, also verified by traffic flow data. Peak evening levels of $\mathrm{H}_{2}$ are also observed later than peak traffic flow, delayed by $\sim 1 \mathrm{~h}$. This delay between vehicle emission and measurement of elevated mole fractions of $\mathrm{H}_{2}$ can be attributed to the mixing time required for emissions to rise from average emission source height to the measurement point, elevated by a few hundred metres from major carriageways. $\mathrm{H}_{2}$ levels drop off more slowly after the evening rush hour as the boundary layer height decreases with more stable nocturnal inversion conditions concentrating pollutants. A very similar pattern is seen for $\mathrm{CO}$, with identical morning and evening rush hour peaks. However, differences can be seen in the amplitude of rush hour peaks and overnight depletion of CO. It is well known that transport emits a much larger mole fraction of $\mathrm{CO}$ than $\mathrm{H}_{2}$ which results in the larger amplitude seen for rush hour peaks of CO (Colls, 1997; Vollmer et al., 2007).
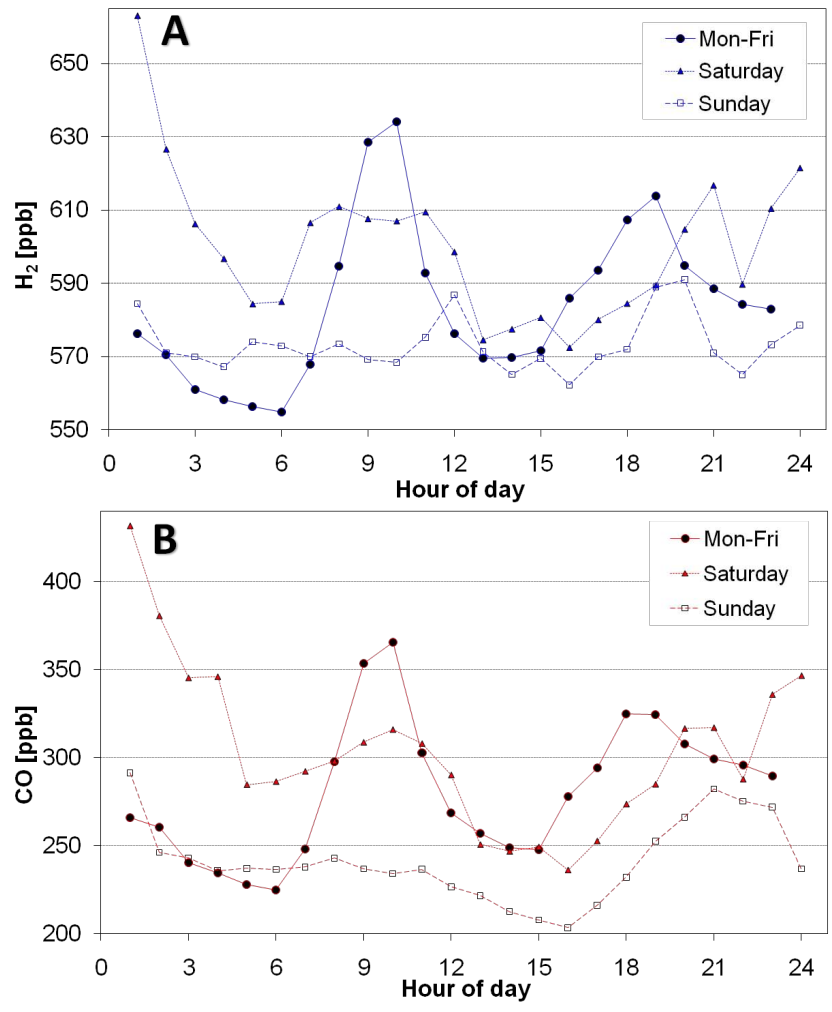

Fig. 5. Hourly averaged (a) $\mathrm{H}_{2}$ and (b) $\mathrm{CO}$ data for weekdays (circles) and Saturday (triangles) and Sundays (squares) for the entire measurement period.

Dry deposition of $\mathrm{CO}$ is reported to be much lower than that of $\mathrm{H}_{2}$ (Yonemura et al., 2000), thus dispersion and mixing is thought to be the primary parameter controlling the $\mathrm{CO}$ decrease seen overnight with concentrations only dropping to $225 \mathrm{ppb}$ compared with $\mathrm{H}_{2}$ which falls to $555 \mathrm{ppb}$, near background levels. Interestingly a similar study by Steinbacher et al. (2007) saw much higher mole fractions of CO during rush hour periods but similar levels of $\mathrm{H}_{2}$ compared with this work. The study by Steinbacher et al., was conducted at a suburban site in Switzerland and observed average morning and evening rush hour peaks of $\sim 520 \mathrm{ppb}$ and $\sim 500 \mathrm{ppb}$ CO respectively, compared with our study in an urban environment, in which morning and evening rush hour peaks of $370 \mathrm{ppb}$ and $325 \mathrm{ppb} \mathrm{CO}$ were observed. However, $\mathrm{CO}$ elevation from early morning minimum was found to be very similar $(\sim 150 \mathrm{ppb} C \mathrm{CO})$ in both studies. Therefore we believe that the higher $\mathrm{CO}$ mole fractions observed during rush hour in the Swiss study was an artefact of the higher background levels observed at the suburban site. One would initially expect the site to have lower background mole factions due to its location further from direct emission sources however local conditions such as meteorology or unknown emission sources may bias this. The difference in transport fleets between the two countries may also contribute to higher background mole fractions of CO. Petrol vehicles are 
known to emit over twice the amount of $\mathrm{CO}$ per km compared with diesel vehicles (Colls, 1997). The UK vehicle fleet is known to consist of approximately $68 \%$ petrol fuelled vehicles, whilst the Swiss fleet contains considerably larger fraction of petrol vehicles (76\%) (Vollmer et al., 2007 and references therein). This may contribute to elevated background levels of $\mathrm{CO}$ but is not likely to be the main cause for the higher mole fractions observed.

\section{2 $\mathrm{H}_{2}$ to $\mathrm{CO}$ ratios}

Figure 6 shows a scatter plot of $\mathrm{H}_{2}$ and $\mathrm{CO}$ over the entire measurement period with background $\mathrm{H}_{2}$ and $\mathrm{CO}$ mole fractions subtracted. It was proven to be essential to subtract background $\mathrm{H}_{2}$ and $\mathrm{CO}$ values prior to plotting and assessment of the molar $\mathrm{H}_{2}$ to $\mathrm{CO}$ ratio, as $\mathrm{H}_{2}$ and $\mathrm{CO}$ show a seasonal cycle offset of two to four months thus it is important to remove the effects of seasonality on the $\mathrm{H}_{2} / \mathrm{CO}$ ratio (Grant et al., 2010). A close correlation can be seen between $\mathrm{H}_{2}$ and $\mathrm{CO}$ with an interesting two branch pattern emerging at higher mole fractions. This is the first study to display such a pattern. Ordinarily, scatter plots of $\mathrm{H}_{2}$ and $\mathrm{CO}$ show a single grouping around a central line with a small amount of scatter. A linear fit was applied to all data, a molar $\mathrm{H}_{2} / \mathrm{CO}$ ratio of $0.53 \pm 0.08$ with an $R^{2}$ value of 0.84 was calculated using reduced major axis regression taking into account the error in both $\mathrm{x}$ and $\mathrm{y}$ axes. Branch $\mathrm{A}$ displayed a molar $\mathrm{H}_{2} / \mathrm{CO}$ ratio of $1.34 \pm 0.12\left(R^{2}=0.95\right)$ from linear fitting. Error from linear fitting was taken into account by use of the regression coefficient (or $\mathrm{R}^{2}$ value). Branch $\mathrm{A}$ was separated from the rest of the dataset according to points highlighted in Figs. 2 and 6 (75 points in total) to enable assessment of its source. The highlighted points accounted for $2 \%$ of the entire dataset. Branch A was analysed by time of day, day of week, weeks during the months, wind speed and wind direction. Points were found to be evenly scattered throughout the day with an equal number of points overnight and during the day. No points in branch A fell between 14:00 and 16:00 local time, we do not believe this to be significant. No significant pattern was observed with day of week, $25 \%$ of points were found to fall at weekend however this is close to the percentage of points which fell at the weekend over the entire dataset (26\%). A large proportion (43\%) of the points which made up branch A were found to occur between the 15th and 17th of February which accounted for $15 \%$ of the entire dataset over this period. Points in branch A mainly (88\%) occurred from the 7th of February until the 2nd of March, 2009. Points in branch A were found to occur at a large range of wind speeds from $3-15 \mathrm{~m} \mathrm{~s}^{-1}$. No correlation was found between nocturnal inversion events (Section 3.4) and the source of Branch A. Wind direction was the only condition where a clear relationship could be demonstrated. Points from branch A were found only to occur between a wind angle of $240^{\circ}$ and $330^{\circ}, 70 \%$ of which were from a westerly direction $\left( \pm 10^{\circ}\right)$. However, all data arriving from

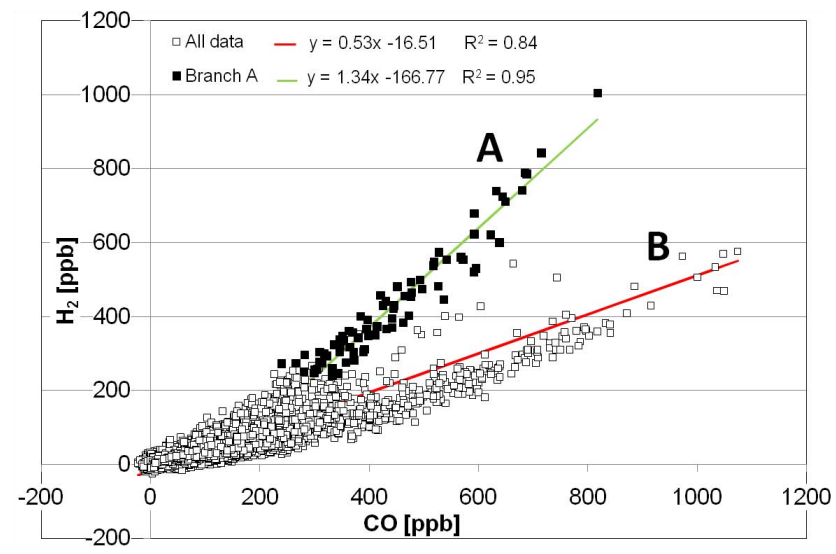

Fig. 6. A scatter plot of individually background subtracted $\mathrm{H}_{2}$ and $\mathrm{CO}$ mole fractions over entire measurement period. Molar $\mathrm{H}_{2} / \mathrm{CO}$ ratios are displayed in the form of a linear fit through the scatter plot in the top of the plot.

this broad westerly region $\left(240^{\circ}-330^{\circ}\right)$ showed data points which encompassed branches A and B. A possible source of elevated $\mathrm{H}_{2}$ compared with $\mathrm{CO}$ in this region is the town of Port Talbot. Situated $85 \mathrm{~km}$ to the west of Bristol, Port Talbot contains a high density of heavy industry including a large industrial gases plant (British Oxygen Company), a steelworks, and a gas fired power plant. Given the very consistent $\mathrm{H}_{2} / \mathrm{CO}$ ratio of branch $\mathrm{A}$, its appearance without an obvious bias for time of day and its onset at a threshold of $3 \mathrm{~m} \mathrm{~s}^{-1}$ suggests a continuous point source some distance away. We believe emissions from some of this industry, possibly the industrial gases plant or the gas turbine engines in the power plant may be the cause for branch A where higher $\mathrm{H}_{2} / \mathrm{CO}$ ratios are observed. Gas turbine engines which use liquid fuels which have a high hydrogen content have been shown to emit high levels of $\mathrm{CO}$ under low firing temperatures due to incomplete combustion (Pavri and Moore, 2003). It is possible that unburnt $\mathrm{H}_{2}$ could also be emitted in similar or higher quantities. This would give rise to a much higher $\mathrm{H}_{2} / \mathrm{CO}$ ratio as seen in Branch A.

\section{3 $\quad \mathrm{H}_{2}$ emissions from transport}

Recently there has been increased interest in $\mathrm{H}_{2} / \mathrm{CO}$ emission ratios from transport (Barnes et al., 2003; Hammer et al., 2009; Steinbacher et al., 2007; Vollmer et al., 2007) as it enables the estimation of large-scale $\mathrm{H}_{2}$ emissions by scaling from $\mathrm{CO}$, which has well constrained regional and global emission inventories. In this study only weekday morning rush hours (7-9 a.m.) were used to calculate $\mathrm{H}_{2}$ emissions from transport, as this period when transport emissions are highest best represents the molar $\mathrm{H}_{2} / \mathrm{CO}$ transport emission ratio. An overall molar $\mathrm{H}_{2} / \mathrm{CO}$ ratio of $0.53 \pm 0.08$ from linear fitting using a reduced major axis regression method of calculation with regression coefficients providing a measure 
Table 1. Literature comparisons of molar $\mathrm{H}_{2} / \mathrm{CO}$ ratios calculated from linear fitting.

\begin{tabular}{llll}
\hline Source & Location & Year of study & $\mathrm{H}_{2} / \mathrm{CO}$ ratio \\
\hline Novelli et al. (1999) & Urban, Busy intersection, Colorado & 1989 & $0.6 \pm 0.1$ \\
Barnes et al. (2003) & Rural but downwind of pollution Harvard Forest, US & $1996-1998$ & 0.34 \\
Steinbacher et al. (2007) & Suburban, Switzerland & $11 / 2002-02 / 2005$ & $0.33 \pm 0.01^{\mathrm{a}}$ \\
Vollmer et al. (2007) & Urban, Highway tunnel, Switzerland & Nov/Dec 2004 & $0.48 \pm 0.12^{\mathrm{b}, \mathrm{c}} 0.51 \pm 0.11^{\mathrm{b}, \mathrm{d}}$ \\
Hammer et al. (2009) & Urban Heidelberg, Germany & $01 / 2005-07 / 2007$ & $0.40 \pm 0.06^{\mathrm{a}}$ \\
This study & Urban, Bristol, UK & $12 / 2008-03 / 2009$ & $0.57 \pm 0.06^{\mathrm{a}} 0.53 \pm 0.08^{\mathrm{b}}$ \\
\hline
\end{tabular}

a: weekday morning rush hour; ${ }^{b}$ : all data; ${ }^{c}$ : mean ratio; ${ }^{d}$ : vehicle weighted ratio.

of the uncertainly in the slope. A molar $\mathrm{H}_{2} / \mathrm{CO}$ ratio of $0.57 \pm 0.06$ was calculated using the same method for weekday morning rush hours (7-9 a.m.). This rush hour ratio agrees well with other urban studies (Table 1) and primarily represents the $\mathrm{H}_{2} / \mathrm{CO}$ emission ratio from transport. Variation of our molar $\mathrm{H}_{2} / \mathrm{CO}$ ratio of 0.53 (and 0.57 for rush hour) from those observed by other urban studies is statistically insignificant with respect to the errors involved in this and other studies. Molar $\mathrm{H}_{2} / \mathrm{CO}$ ratios reported by Steinbacher et al. (2007) are lower $(0.33 \pm 0.01)$ due to the suburban nature of this site. Barnes et al. (2003) reported a molar ratio of 0.34 from a rural location downwind of high pollution where much dilution of pollution plumes would have occurred prior to sampling. Hammer et al. (2009) reported a molar ratio of $0.40 \pm 0.06$ from an urban site. This molar ratio, lower than that calculated in this study could be attributed to differing local conditions such as location of industry, incinerators and reduced traffic levels which may alter the $\mathrm{H}_{2} / \mathrm{CO}$ ratio. If there are large industrial emissions close to the measurement location $\mathrm{H}_{2} / \mathrm{CO}$ ratios may be altered, as a recent study found chimney stack emissions from incinerators and domestic heating to produce a significantly reduced ratio compared with emissions from vehicle exhaust (M. K. Vollmer, personal communication, 2009). Winter $\mathrm{H}_{2} / \mathrm{CO}$ ratios have been found to display a higher correlation coefficient than summer ratios, as increased mixing and dilution during summer months caused by thermal convection alters the direct emission ratio (Steinbacher et al., 2007). Increased depletion of $\mathrm{H}_{2}$ due to dry deposition to the soil has also been found to alter $\mathrm{H}_{2} / \mathrm{CO}$ ratios less in winter than summer (Grant et al., 2010). Therefore we believe $\mathrm{H}_{2} / \mathrm{CO}$ ratios derived solely from winter data (as used in this study) are thought to be more accurate in predicting $\mathrm{H}_{2}$ emissions from transport sources.

$\mathrm{H}_{2}$ emissions from transport and other anthropogenic sources are very poorly constrained, with a scarcity of bottom up emissions estimates. Thus top down estimates are produced as a best guess constrained by bottom up emission estimates for $\mathrm{CO}$, a much more widely studied tropospheric pollutant. The mass of $\mathrm{H}_{2}$ emissions was calculated using a simple approach incorporating annual $\mathrm{CO}$ emissions and the measured $\mathrm{H}_{2} / \mathrm{CO}$ emissions ratio (Dunse et al., 2005). An- nual $\mathrm{CO}$ emissions for Bristol are estimated to be $7.9 \mathrm{Gg} / \mathrm{yr}$, with $4578 \mathrm{Gg} \mathrm{CO} / \mathrm{yr}$ from UK transport emissions (NAEI, 2006a; NAEI, 2006b). Applying a rush hour $\mathrm{H}_{2} / \mathrm{CO}$ ratio of $0.57 \pm 0.06$, Bristol's $\mathrm{H}_{2}$ source can be estimated as $325 \pm 67 \mathrm{Mg} \mathrm{H}_{2} / \mathrm{yr}$, this is considered an upper estimate of overall $\mathrm{H}_{2}$ emissions in the area as it has been suggested that $\mathrm{a}_{2} / \mathrm{CO}$ ratio of much less than 0.5 may be more appropriate for non-transport sources of $\mathrm{H}_{2}$ (Grant et al., 2010). UK vehicle transport emissions of $188 \pm 39 \mathrm{Gg} \mathrm{H}_{2} / \mathrm{yr}$ were also estimated using a transport emissions ratio of $0.57 \pm 0.06$.

Since diesel vehicles are known to produce significantly less $\mathrm{H}_{2}$ than their petrol counterparts (Vollmer et al., 2007), to predict global $\mathrm{H}_{2}$ emissions from transport, one must consider the proportion of diesel and petrol fuelled vehicles worldwide. The world fleet has been estimated to consist of $\sim 92 \%$ petrol vehicles (Fulton and Eads, 2004). However, as our molar $\mathrm{H}_{2} / \mathrm{CO}$ emissions ratio was measured in a fleet of $68 \%$ petrol vehicles we must assume our ratio of 0.57 is at the lower end of the emissions ratio (Anderson, 2008) which would produce an emission of $7.7 \pm 2.2 \mathrm{Tg} \mathrm{H}_{2} / \mathrm{yr}$. Assuming global CO emissions from road transport of $186 \mathrm{Tg} \mathrm{CO} / \mathrm{yr}$ for 2000 taken from the EDGAR v3.2 database (Olivier et al., 2002). We can also scale up our molar $\mathrm{H}_{2} / \mathrm{CO}$ emissions ratio in the same manner as Vollmer et al. (2007) to produce an estimate for the world fleet of $92 \%$ petrol vehicles. Our emission ratio of 0.57 can be scaled up to 0.63 assuming a pure petrol fleet which is then reduced to 0.61 to account for the $8 \%$ of diesel vehicles globally. This scaled ratio estimates $8.1 \pm 2.3 \mathrm{Tg} \mathrm{H}_{2} / \mathrm{yr}$ is produced from road transport globally, with uncertainties in scaling of an emissions ratio based on the percentage of vehicle types and the error associated with the $\mathrm{CO}$ emissions estimate. This is within the wide range quoted by Novelli et al. (1999) of 5-20 Tg $\mathrm{H}_{2} / \mathrm{yr}$. It is at the upper end of the range of $4.2-8.1 \mathrm{Tg} \mathrm{H}_{2} / \mathrm{yr}$ quoted by Vollmer et al. (2007). Differences between our study and that of Vollmer and co-workers are due to the lower molar $\mathrm{H}_{2} / \mathrm{CO}$ emission ratio measured in that study but also due to the range of different methods of calculation used in the study by Vollmer and co-workers. The lower estimate of $4.2 \mathrm{Tg} \mathrm{H}_{2} / \mathrm{yr}$ produced by Vollmer was formed by use of the $\mathrm{H}_{2} / \mathrm{CO}_{2}$ emissions ratio from vehicles and a global road vehicles $\mathrm{CO}_{2}$ emissions estimate. 


\subsection{Nocturnal depletions of $\mathrm{H}_{2}$ and $\mathrm{CO}$}

Over several nights during the measurement period strong nocturnal depletions of $\mathrm{H}_{2}$ and $\mathrm{CO}$ were observed, thought to occur due to a combination of mixing and dry deposition for $\mathrm{CO}$ and dry deposition for $\mathrm{H}_{2}$. The deposition velocity can be calculated if the height of the boundary layer is known. The boundary layer height $(h)$ in meters can be calculated according to the equation:

$h=\sqrt[3]{\frac{\gamma^{2} \cdot T \cdot u_{*}^{4}}{f \cdot \kappa \cdot g}(-d T / d t)}$

where $\gamma=0.4$ is the Zilitinkevich constant, $T$ is the mean temperature in Kelvin, $f$ is the coriolis parameter for Bristol, $g$ is the acceleration of gravity, $d T / d t$ is the mean cooling rate and $u_{*}$ is the friction velocity (Garland and Derwent, 1979; Moxley and Cape, 1997). Friction velocity was calculated according to the equation:

$u(z)=\frac{u_{*}}{\kappa} \cdot \ln \frac{z}{z_{0}}$

where $u$ is wind speed at height $z=10 \mathrm{~m}$, the von Karman constant $\kappa=0.4$ and the roughness length $\left(z_{o}\right)$ for an urban area of $0.4 \mathrm{~m}$ (Stull, 1988), which resulted in a mean friction velocity of $1.05 \mathrm{~m} \mathrm{~s}^{-1}$ for the Bristol area. Although this is a rough estimate of the boundary layer height making many assumptions, such as a constant cooling rate and average friction velocity for each event, it is preferable to using a constant boundary layer height of $100 \mathrm{~m}$ for instance (suitable for winter nighttime). This method allows variation of boundary layer height with wind speed and turbulence therefore results in a more refined estimation of deposition velocities.

Calculation of the boundary layer height enables estimation of the deposition velocity, $v_{d}\left(\mathrm{~m} \mathrm{~s}^{-1}\right)$ according to the equation:

$v_{d}=k_{1} h$

where $k_{1}$ is the first-order decay constant for the decrease in $X\left(\mathrm{~s}^{-1}\right)$ (where $X=\mathrm{H}_{2}$ or CO mole fractions, assuming no mixing or dilution occurs). The decrease in $X$ follows first order kinetics and can be written as:

$-\frac{d[X]}{d t}=k_{1}[X] \quad$ or $\quad[X]_{t}=[X]_{0} e^{-k_{1} t}$

Where $[X]_{0}$ is the mole fraction at approximately $11 \mathrm{p} . \mathrm{m}$. local time depending on the night-time event and $[\mathrm{X}]_{t}$ is the mole fraction at time $t$ after $11 \mathrm{p}$.m. Decay rate constants $\left(k_{1}\right)$ for $\mathrm{H}_{2}$ and $\mathrm{CO}$ ranged from $2.26 \times 10^{-6}$ to $1.19 \times 10^{-5} \mathrm{~s}^{-1}$ and $1.84 \times 10^{-5}$ to $6.31 \times 10^{-5} \mathrm{~s}^{-1}$, respectively.

The boundary layer height was calculated for each night time event and displayed a range of 18 to $100 \mathrm{~m}$, well within reported ranges of 20-30 m (Mahrt and Vickers,
2002), 50-150 m (Salmond and McKendry, 2002) and 100$500 \mathrm{~m}$ before sunrise (Stull, 1988). $\mathrm{H}_{2}$ deposition velocities were calculated with individual boundary layer heights for each nocturnal event. A range of $0.9 \pm 0.2-5.7 \pm 1.1 \times$ $10^{-4} \mathrm{~m} \mathrm{~s}^{-1}$, with a mean of $2.2 \pm 1.5 \times 10^{-4} \mathrm{~m} \mathrm{~s}^{-1}(1 \sigma)$ and a median of $1.8 \times 10^{-4} \mathrm{~m} \mathrm{~s}^{-1}$ were found over the fourteen nocturnal events studied. This mean value agrees well with that of $2.4 \pm 1.3 \times 10^{-4} \mathrm{~m} \mathrm{~s}^{-1}$ (Yver et al., 2009) and $3.0 \times 10^{-4} \mathrm{~m} \mathrm{~s}^{-1}$ (Hammer and Levin, 2009) both measured in urban environments but using a different method. However our value is slightly higher than another urban estimate of $0.5-1.0 \times 10^{-4} \mathrm{~m} \mathrm{~s}^{-1}$ (Steinbacher et al., 2007). Our estimate is smaller than $4.8 \pm 1.3 \times 10^{-4} \mathrm{~m} \mathrm{~s}^{-1}$ (Gerst and Quay, 2001) and a recent modelling estimate of $5.3 \times 10^{-4} \mathrm{~m} \mathrm{~s}^{-1}$ (Sanderson et al., 2003) but within the wide range reported $0-10 \times 10^{-4} \mathrm{~m} \mathrm{~s}^{-1}$ from flux chamber measurements (Yonemura et al., 1999).

CO deposition velocities displayed a range of $4.2 \pm 0.8-$ $31 \pm 6.2 \times 10^{-4} \mathrm{~m} \mathrm{~s}^{-1}$, with a mean of $13 \pm 8 \times 10^{-4} \mathrm{~m} \mathrm{~s}^{-1}$ $(1 \sigma)$ and a median of $8.8 \times 10^{-4} \mathrm{~m} \mathrm{~s}^{-1}$ over the fourteen nocturnal events. Two other studies using similar methods have estimated deposition velocities. A study in a semirural area approximately $4 \mathrm{~km}$ outside Edinburgh a $\mathrm{CO}$ deposition velocity of $11 \times 10^{-4} \mathrm{~m} \mathrm{~s}^{-1}$ was estimated (Moxley and Cape, 1997), which agrees well with our work. However a value of $0.4 \times 10^{-4} \mathrm{~m} \mathrm{~s}^{-1}$ was calculated at a costal background site (Simmonds et al., 2000), significantly lower than our estimate which is unexpected as with a larger soil area exposed at this rural area one would conversely expect higher deposition velocities. Other estimates range from $0.56-7.6 \times 10^{-4} \mathrm{~m} \mathrm{~s}^{-1}$ mainly from chamber studies in the field (Table 2), significantly lower than the mean CO deposition velocity but close to the median $\mathrm{CO}$ deposition calculated in this study.

As expected the deposition velocities of $\mathrm{H}_{2}$ and $\mathrm{CO}$ were closely correlated $\left(R^{2}=0.61\right)$, however, the mean ratio of $\mathrm{H}_{2} / \mathrm{CO}$ deposition velocities during individual events (0.19) was significantly lower than previously reported. Yonemura et al. (1999) reported a ratio of $\mathrm{H}_{2} / \mathrm{CO}$ deposition of 1.55 , whilst Simmonds et al. (2000) reported an extremely large ratio of 6.5. Another study by Yonemura et al. (2000b) displayed a high $\mathrm{H}_{2} / \mathrm{CO}$ correlation coefficient of 0.88 in an arable field, with a $\mathrm{H}_{2} / \mathrm{CO}$ deposition velocity ratio of 1.79 , however the forested site in this study showed much lower correlation $\left(R^{2}=0.41\right)$ with a $\mathrm{H}_{2} / \mathrm{CO}$ deposition velocity ratio of 2.33. In light reported ratios of $\mathrm{H}_{2} / \mathrm{CO}$ deposition in literature, our $\mathrm{H}_{2} / \mathrm{CO}$ deposition velocity ratio is unusually small $(<1)$, showing much larger $\mathrm{CO}$ deposition velocities than $\mathrm{H}_{2}$. This is surprising as the law of molecular diffusivity states that lighter gases diffuse into the soil much faster than heavier gases. One may therefore expect $\mathrm{H}_{2}$ to have a higher deposition velocity than $\mathrm{CO}$ as diffusion into the soil surface was found to be the primary parameter controlling deposition of $\mathrm{H}_{2}$ (Schmitt et al., 2009). However, CO deposition may be controlled by kinetics of the biological 
Table 2. Comparison of CO deposition velocities.

\begin{tabular}{llll}
\hline Method & Vegetation & $\mathrm{CO} v_{d}\left(\times 10^{4} \mathrm{~m} \mathrm{~s}^{-1}\right)$ & Reference \\
\hline Decay rate & Mixed & $11(2.6-33)$ & Moxley and Cape (1997) \\
Open flow chamber & Andisol field & $0-6$ & Yonemura et al. (1999) \\
$\mathrm{CO}_{2}$ tracer method & Grass field & 3.4 & Yonemura et al. (2000a) \\
Flux chamber & Arable field Forest & $2.4 \pm 1.6(0-7) 2.7 \pm 0.6(1.5-4.5)$ & Yonemura et al. (2000b) \\
Closed flux chamber & Pine forest Spruce forest & 0.851 .5 & Zepp et al. (1997) \\
Ozone tracer method & Rural mixed & 0.4 & Simmonds et al. (2000) \\
Static chamber & Agricultural Forest & 0.140 .23 & Moxley and Smith (1998) \\
Decay rate & Urban mixed & $12.7 \pm 8.4(1 \sigma)$ mean 8.79 median & Our work \\
\hline
\end{tabular}

uptake process as well as diffusion which results in this unusual uptake ratio. Loss of $\mathrm{CO}$ by reaction with the $\mathrm{OH}$ radical can be ruled out, as $\mathrm{CO}$ loss of $3.3 \times 10^{-5} \mathrm{~s}^{-1}$ (mean loss from night-time events) would require a night-time $\mathrm{OH}$ radical concentration of $1.6 \times 10^{8}$ molecules $\mathrm{cm}^{-3}$ which is not possible under night-time conditions. Night-time $\mathrm{OH}$ radical concentrations in the range of $2 \pm 1.5 \times 10^{5}$ molecules $\mathrm{cm}^{-3}$ have been measured and modelled in recent studies (Emmerson and Carslaw, 2009; Geyer et al., 2003) whilst daytime average $\mathrm{OH}$ is thought to be $1 \times 10^{6}$ molecules $\mathrm{cm}^{-3}$ (Khan et al., 2008; Prinn et al., 2005). Reaction of CO with the nitrate radical $\left(\mathrm{NO}_{3}\right)$ is too slow to account for any significant loss (Boyd et al., 1991).

\section{Conclusions}

High-frequency measurements of $\mathrm{H}_{2}$ and $\mathrm{CO}$ were performed at an urban site in the UK from December 2008 to March 2009. To our knowledge these are the first published measurements from an urban UK site, influenced predominantly by vehicle emissions. The site was found to be heavily influenced by transport emissions, where a clear transport related diurnal cycle was observed. However, local meteorological conditions of temperature, wind speed and direction were also found to influence the high-frequency measurements taken at the site, which may have implications for future analysis of measurements taken in an urban environment. Future studies should consider placing urban measurement stations in areas less prone to strong winds which disrupt urban emission patterns. A scatter plot of $\mathrm{H}_{2}$ versus $\mathrm{CO}$ revealed an unexpected two population pattern which has not been observed in any previous studies and whose origin proved difficult to elucidate. An industrial gases plant and power plant were suggested as the possible source of the higher $\mathrm{H}_{2} / \mathrm{CO}$ ratio, a higher ratio than observed in any previous studies. However, measurements of specific sources such as this must be carried out for this hypothesis to be verified. We suggest that further investigation into the $\mathrm{H}_{2} / \mathrm{CO}$ emission ratios from poorly constrained sources of $\mathrm{H}_{2}$ such as chimney stack emissions from industry, incinerator and avi- ation emissions would aid the assessment of future studies, particularly in the analysis of $\mathrm{H}_{2} / \mathrm{CO}$ ratio anomalies. This would enable more accurate estimates of $\mathrm{H}_{2}$ emissions from combustion sources globally.

$\mathrm{H}_{2}$ and $\mathrm{CO}$ deposition velocities were calculated over stable periods when a clear decay of both species was observed. $\mathrm{CO}$ was found to have a much higher deposition velocity than $\mathrm{H}_{2}\left(1.3 \times 10^{-3}\right.$ and $2.2 \times 10^{-4} \mathrm{~m} \mathrm{~s}^{-1}$ respectively). The source of this unusual result was investigated, however no conclusive evidence was found for increased loss of $\mathrm{CO}$ over $\mathrm{H}_{2}$ during stable night time inversion events.

Acknowledgements. AG thanks "EuroHydros - A European Network for Atmospheric Hydrogen Observations and studies", a part of the 6th EU framework program FP6-2005-Global-4 and Bristol ChemLabS for funding.

Edited by: R. Harley

\section{References}

Anderson, D.: Transport Statistics Great Britain, 34th edition, Section 9: Vehicles, Government Document, available at: http://www.dft.gov.uk/pgr/statistics/datatablespublications/ tsgb/2008edition/, last access: June 2009, Department for Transport, 2008.

Barnes, D. H., Wofsy, S. C., Fehlau, B. P., Gottlieb, E. W., Elkins, J. W., Dutton, G. S., and Novelli, P. C.: Hydrogen in the atmosphere: observations above a forest canopy in a polluted environment, J. Geophys. Res., 108, 4197, doi:10.1029/2001JD001199, 2003.

Bergamaschi, P., Hein, R., Heimann, M., and Crutzen, P. J.: Inverse modeling of the global $\mathrm{CO}$ cycle 1 , Inversion of $\mathrm{CO}$ mixing ratios, J. Geophys. Res., 105(D2), 1909-1927, 2000.

Boyd, A. A., Canosa-Mas, C. E., King, A. D., Wayne, R. P., and Wilson, M. R.: Use of a stopped-flow technique to measure the rate constants at room temperature for reactions between the nitrate radical and various organic species, J. Chem. Soc., Faraday Trans., 87, 2913-2919, 1991.

Bristol City Council, Data received from the Institute of Transport studies at Bristol City Council, United Kingdom, 2009.

Colls, J.: Air Pollution: An Introduction, E\&FN Spon, London, 1997. 
Conrad, R.: Biogeochemistry and ecophysiology of atmospheric $\mathrm{CO}$ and $\mathrm{H}_{2}$, Adv. Microb. Ecol., 10, 231-283, 1988.

Dunse, B. L., Steele, L. P., Wilson, S. R., Fraser, P. J., and Krummel, P. B.: Trace gas emissions from Melbourne, Australia, based on AGAGE observations at Cape Grim, Tasmania, 1995-2000, Atmos. Environ., 39, 6334-6344, 2005.

Emmerson, K. M. and Carslaw, N.: Night-time radical chemistry during the TORCH campaign, Atmos. Environ., 43, 3220-3226, 2009.

Fulton, L. and Eads, G.: IEA/SMP model documentation and reference case projection. Auxilliary material to: Mobility 2030: Meeting the challenges to sustainability, The Sustainability mobility Project, IEA/CRA, 2004.

Garland, J. A. and Derwent, R. G.: Destruction at the ground and the diurnal cycle of concentration of ozone and other gases, Q. J. Roy. Meteor. Soc., 105, 169-183, 1979.

Gerst, S. and Quay, P.: Deuterium component of the global molecular hydrogen cycle, J. Geophys. Res., 106, 5021-5031, 2001.

Geyer, A., Bächmann, K., Hofzumahaus, A., Holland, F., Konrad, S., Klüpfel, T., Pätz, H. W., Perner, D., Mihelcic, D., and Schäfer, H. J.: Nighttime formation of peroxy and hydroxyl radicals during the BERLIOZ campaign: observations and modeling studies, J. Geophys. Res., 108, 8249, doi:10.1029/2001JD000656, 2003.

Grant, A., Witham, C. S., Simmonds, P. G., Manning, A. J., and O'Doherty, S.: A 15 year record of high-frequency, in situ measurements of hydrogen at Mace Head, Ireland, Atmos. Chem. Phys., 10, 1203-1214, doi:10.5194/acp-10-1203-2010, 2010.

Hammer, S. and Levin, I.: Seasonal variation of the molecular hydrogen uptake by soils inferred from continuous atmospheric observations in Heidelberg, Southwest Germany, Tellus B, 61, 556565, 2009

Hammer, S., Vogel, F., Kaul, M., and Levin, I.: The $\mathrm{H}_{2} / \mathrm{CO}$ ratio of emissions from combustion sources: comparison of top-down with bottom-up measurements in Southwest Germany, Tellus B, 61, 547-555, 2009.

Jordan, A. and Steinberg, B.: Calibrating Measurements of Atmospheric Hydrogen, Atmos. Meas. Tech. Discuss., in preparation, 2010.

Khan, M. A. H., Ashfold, M. J., Nickless, G., Martin, D., Watson, L. A., Hamer, P. D., Wayne, R. P., Canosa-Mas, C. E., and Shallcross, D. E.: Night-time $\mathrm{NO}_{3}$ and $\mathrm{OH}$ radical concentrations in the UK inferred from hydrocarbon measurements, Atmos. Sci. Lett., 9, 140-146, 2008.

Khan, M. A. H., Mead, M. I., White, I. R., Golledge, B., Nickless, G., Knights, A., Martin, D., Rivett, A. C., Greally, B. R., and Shallcross, D. E.: Year-long measurements of $\mathrm{C}_{1}-\mathrm{C}_{3}$ halocarbons at an urban site and their relationship with meteorological parameters, Atmos. Sci. Lett., 10, 75-86, 2009.

Mahrt, L. and Vickers, D.: Contrasting vertical structures of nocturnal boundary layers., Bound.-Lay. Meteorol., 105, 351-363, 2002.

Martin, D., Price, C. S., White, I. R., Nickless, G., Dobre, A., and Shallcross, D. E.: A study of pollutant concentration variability in an urban street under low wind speeds, Atmos. Sci. Lett., 9, 147-152, 2008.

Moxley, J. M. and Cape, J. N.: Depletion of carbon monoxide from the nocturnal boundary layer, Atmos. Environ., 31, 1147-1155, 1997.
Moxley, J. M. and Smith, K. A.: Factors affecting utilisation of atmospheric CO by soils, Soil Biol. Biochem., 30, 65-79, 1998.

NAEI - National Atmospheric Emissions Inventory: CO source emissions estimates for the city of Bristol, available at: http:// www.naei.org.uk/datawarehouse/, last access: June 2009, 2006 a.

NAEI - National Atmospheric Emissions Inventory: UNECE Emission Estimates, CO emissions estimates for the UK, available at: http://www.naei.org.uk/data_warehouse.php, las access: June 2009, 2006 b.

Novelli, P. C., Lang, P. M., Masarie, K. A., Hurst, D. F., Myers, R., and Elkins, J. W.: Molecular hydrogen in the troposphere: Global distribution and budget, J. Geophys. Res., 104, 3042730444, 1999.

Olivier, J., Berdowski, J. J. M., Peter, J. A. H. W., Bakker, J., Visschedijk, A. J. H., and Bloos, J. P. J.: Applications of EDGAR emission database for global atmospheric research, Technical Report RIVM report no. 773301001, NOP report no. 410200051, RIVM, Bilthoven, The Netherlands, 2002.

Pavri, R. and Moore, G. D.: Gas Turbine Emissions and Control, GE Energy Servies, Atlanta, GA available at www.gepower. com/prod-serv/products/tech-docs/en/downloads/ger4211.pdf, accessed on: 25th April, 2010, 2003.

Price, H., Jaeglé, L., Rice, A., Quay, P., Novelli, P. C., and Gammon, R.: Global budget of molecular hydrogen and its deuterium content: constraints from ground station, cruise, and aircraft observations, J. Geophys. Res., 112, D22108, doi:10.1029/2006JD008152, 2007.

Prinn, R. G., Huang, J., Weiss, R. F., Cunnold, D. M., Fraser, P. J., Simmonds, P. G., McCulloch, A., Harth, C., Reimann, S., Salameh, P., O’Doherty, S., Wang, R. H. J., Porter, L. W., Miller, B. R., and Krummel, P. B.: Evidence for variability of atmospheric hydroxyl radicals over the past quarter century, Geophys. Res. Lett., 32, L07809, doi:10.1029/2004GL022228, 2005.

Rivett, A. C., Martin, D., Gray, D. J., Price, C. S., Nickless, G., Simmonds, P. G., ODoherty, S. J., Greally, B. R., Knights, A., and Shallcross, D. E.: The role of volatile organic compounds in the polluted urban atmosphere of Bristol, England, Atmos. Chem. Phys., 3, 1165-1176, doi:10.5194/acp-3-1165-2003, 2003.

Salmond, J. A. and McKendry, I. G.: Secondary ozone maxima in a very stable nocturnal boundary layer: observations from the Lower Fraser Valley, BC, Atmos. Environ., 36, 5771-5782, 2002.

Sanderson, M. G., Collins, W. J., Derwent, R. G., and Johnson, C. E.: Simulation of global hydrogen levels using a Lagrangian three-dimensional model, J. Atmos. Chem., 43, 15-28, 2003.

Schmitt, S., Hanselmann, A., Wollschlager, U., Hammer, S., and Levin, I.: Investigation of parameters controlling the soil sink of atmospheric molecular hydrogen, Tellus B, 61, 416-423, 2009.

Simmonds, P. G., Derwent, R. G., O'Doherty, S., Ryall, D. B., Steele, L. P., Langenfelds, R. L., Salameh, P., Wang, H. J., Dimmer, C. H., and Hudson, L. E.: Continuous high-frequency observations of hydrogen at the Mace Head baseline atmospheric monitoring station over the 1994-1998 period, J. Geophys. Res., 105, 12105-12121, 2000.

Steinbacher, M., Fischer, A., Vollmer, M. K., Buchmann, B., Reimann, S., and Hueglin, C.: Perennial observations of molecular hydrogen $\left(\mathrm{H}_{2}\right)$ at a suburban site in Switzerland, Atmos. Environ., 41, 2111-2124, 2007. 
Stull, R. B.: An introduction to Boundary Layer Meteorology, Kluwer Academic Publishers, Dordrecht, 666 pp., 1988.

Vollmer, M. K., Juergens, N., Steinbacher, M., Reimann, S., Weilenmann, M., and Buchmann, B.: Road vehicle emissions of molecular hydrogen $\left(\mathrm{H}_{2}\right)$ from a tunnel study, Atmos. Environ., 41, 8355-8369, 2007.

Xiao, X., Prinn, R. G., Simmonds, P., Novelli, P. C., Huang, L., Langenfelds, R. L., O’Doherty, S., Krummel, P. B., Fraser, P. J., Porter, L. W., Weiss, R. F., Salameh, P., and Wang, H. J.: Optimal estimation of the soil uptake rate of molecular hydrogen from the Advanced Global Atmospheric Gases Experiment and other measurements, J. Geophys. Res., 112, D07303, doi:10.1029/2006JD007241, 2007.
Yonemura, S., Kawashima, S., and Tsuruta, H.: Continuous measurements of $\mathrm{CO}$ and $\mathrm{H}_{2}$ deposition velocities onto an andisol: uptake control by soil moisture, Tellus B, 51, 688-700, 1999.

Yonemura, S., Kawashima, S., and Tsuruta, H.: Carbon monoxide, hydrogen, and methane uptake by soils in a temperate arable field and a forest, J. Geophys. Res., 105, 14347-14362, 2000.

Yver, C., Schmidt, M., Bousquet, P., Zahorowski, W., and Ramonet, M.: Estimation of the molecular hydrogen soil uptake and traffic emissions at a suburban site near Paris through hydrogen, carbon monoxide, and radon-222 semicontinuous measurements, J. Geophys. Res, 114, D18304, doi:10.1029/2009JD012122, 2009. 